\title{
ТУРИСТСКАЯ ОТРАСЛЬ КАК СФЕРА ЭНЕРГОПОТРЕБЛЕНИЯ
}

Статья посвящена вопросам энергосбережения и энергоэффективности в туристской отрасли. Цель статьи состоит в обосновании путей рационализации использования энергоресурсов туристской сферы России. Для достижения иели были идентифицированы проблемы туристской отрасли России как энергопотребителя и намечен вектор будущего развития отрасли с учетом рационализации энергопотребления. Выявлен системный характер проблем энергоэффективности и энергосбережения в экономике России. Разработаны рекомендации по снижению энергопотребления в гостиничном бизнесе.

Ключевые слова: туризи, энергопотребление, энергосбереэсение, энергоэффективность, гостиничные бизнес.

Lyudmila Guzikova, Aleksander Kolesnikov, Ksenia Shekhmatova TOURIST INDUSTRY AS THE SPHERE OF ENERGY CONSUMPTION

The article is devoted to energy saving and energy efficiency in the tourism industry. The article purpose is to determine the ways to rationalize the use of energy resources by the Russian tourism industry. To achieve the goal, the problems of tourism industry in Russia as an energy consumer were identified. The vector of future industry development was described taking into account the rationalization of energy consumption. The system nature of energy efficiency and energy saving problems in the Russian economy has been revealed. Recommendations on reducing energy consumption in the hotel business are developed.

Key words: tourism, energy consumption, energy saving, energy efficiency, hotel business.

Bведение / Introduction. В понятие «туризм» вкладываются, как правило, формирующие общее впечатление об отдыхе составляющие: пассивная или активная рекреация, культурное времяпровождение, знакомство с гастрономией региона и общая удовлетворенность качеством и уровнем сервиса. Путешественник как получатель туристских услуг нацелен на получение высококачественного сервиса и положительных эмоций от поездки, а конечной целью участников туристско-рекреационного комплекса является получение прибыли за счет удовлетворения в полной мере нужд путешественника как конечного потребителя и завоевания его лояльности.

Большинство современных технологий в сфере туризма имеют высокую стоимость и требуют значительных объемов инвестиций для их покупки, установки, корректного запуска и включения в состав действующих систем. Безусловно, все затраты должны в конечном итоге быть перекрыты полученным экономическим эффектом от внедрения указанных технологий.

Многие исследователи, изучающие развитие туризма, говорят о мировой тенденции формирования «экокластеров», включающих в себя «умные зоны» рекреационной инфраструктуры дестинаций: предприятия общепита, транспортной инфраструктуры и элементов транспортного сообщения, предприятия досуговой сферы, торговые центры, отделения банков и т. д. [6, с. 112].

Как показывают результаты опроса, проводившегося исследователями Корнельского университета, значительная часть респондентов готова платить больше за услуги и продукты, отвечающие современным экологическим нормам, $[6$, с. 25], что можно объяснить как растущей сознательностью потребителей услуг, так и их стремлением сделать свой отдых максимально безопасным с экологической точки зрения. 
Цель данной статьи - обосновать пути рационализации использования энергетических ресурсов туристской отрасли в России. Для достижения поставленной цели необходимо идентифицировать проблемы туристской отрасли России как энергопотребителя и наметить вектор будущего развития отрасли с учетом рационализации энергопотребления.

Общая тенденция такова, что в сфере услуг наряду с качественными изменениями происходит активный количественный рост. Рассматривая текущее положение дел в туризме как одной из важных отраслей экономики, следует учитывать, что более половины отечественного ВВП производится в сфере услуг. Туристская отрасль, являясь ключевым элементом международной системы сервиса, оказывает прямое влияние на экономику России, определяет вектор развития и направленность потребительской активности. На рубеже 90-х гг. XX вв. сфере услуг создавалось $23 \%$ ВВП России и работало чуть менее $40 \%$ от общего числа занятых. К настоящему времени положение дел сушественно изменилось: указанные выше показатели составляют соответственно $53 \%$ и $50 \%$. Общая численность занятых в сфере услуг составляет порядка 32 млн человек, причем 5,3 млн человек из этого числа (16\%) заняты в транспортном и других сопроводительных видах сервиса. Согласно статистике, 90-е годы характеризовались минимальным уровнем всех расходов из общей суммы затрат, что составляло на тот момент всего $15 \%$. Нынешнее положение дел, даже в условиях кризиса, отражает динамику увеличения роста расходов, которые составляют более $23 \%$. К позитивным тенденциям в сфере туризма можно отнести расширение ассортимента услуг и повышение их качества. По темпам роста объемов производства сфера услуг в целом и туристская сфера в частности стабильно лидируют среди других сфер народного хозяйства.

Если проанализировать проблему энергопотребления в масштабе рекреационных зон всей страны, то первое, что следует принять во внимание, это высокий уровень энергоемкости российской экономики. Как указывает В. Е. Печерица, ни одна из стран, являющихся наиболее крупными потребителями энергии в мире, не потребляет такого количества энергии на единицу ВВП, как Россия [7, с. 97]. В среднем в России расход энергии на единицу ВВП на 30 \% превышает аналогичные показатели других индустриально развитых стран.

Основной мыслью, которая прослеживается в литературе по вопросам энергопотребления в российской экономике, является согласие авторов в необходимости массового внедрения энергосберегающих технологий. Это обусловлено тем, что энергосбережение может рассматриваться как фактор экономического развития. Осуществление мер по экономии затрат энергии и по возможности сокращению её использования без получения практической пользы должно широко внедряться в каждодневную практику. Такие меры помогут увеличить количество мощностей прямого использования, улучшить экономическую обстановку и повысить уровень ответственности граждан в плане рационализации использования энергии как ресурса [7, с. 35].

Результаты и обсуждение / Results and discussion. Современная государственная политика России в сфере регулирования ценообразования на энергоресурсы ориентирована на выравнивание в перспективе внутренних и мировых цен. В научных работах российских авторов выражается и обосновывается мнение, что такие меры приведут к семикратному росту цен на газ и двукратному росту цен на нефть и нефтепродукты. Естественно, что за этим последует рост размера платы за энергоресурсы, который затронет интересы всех энергопотребителей [6, с. 67].

Если говорить об актуальности внедрения мероприятий по энергоэффективности и энергосбережению в туристической отрасли, то стоит указать основные факторы нецелесообразного использования ресурсов:

1) на государственном уровне:

- запредельный уровень энергоёмкости в ВВП;

- вредное воздействие энергоемких составляющих на экологическую обстановку;

- нецелесообразное использование распределительных сетей; 
2) на уровне предприятий и организаций:

- высокий удельный вес затрат на энергию в себестоимости услуг;

- завышенные требования к пропускной способности распределительных сетей предприятий;

- прямая зависимость от поставщиков энергии [6, с. 45].

Основными мерами, которые могут быть приняты на государственном уровне с целью повсеместного внедрения энергосбережения, можно считать:

1) разработку нормативно-правовой базы в сфере использования энергоэффективных технологий, основанной на необходимости модернизации существующей законодательной и нормативной системы регулирования исходя из опыта стран, лидирующих в сфере внедрения энергоэффективных технологий;

2) разработку механизмов экономического стимулирования. В мировой практике используется широкий спектр экономических мер и механизмов, направленных на стимулирование внедрения экологических технологий. Первоочередной мерой можно считать принятие природоохранных норм и законов, что позволяет придать внедрению экологических технологий всеобщий и обязательный характер и установить четкие критерии. Широко применяются налоговое стимулирование, предоставление имущественных и неимущественных льгот физическим и юридическим лицам. Налоговые льготы частично покрывают затраты на повышение энергоэффективности объектов. Комплексное функционирование указанных механизмов должно обеспечиваться разработкой системного подхода к повышению уровня энергоэффективности строящихся и уже введенных в эксплуатацию объектов туристской инфраструктуры. В первую очередь это относится к об́ъектам гостиничного комплекса;

3) организация системы инвестирования в энергоэффективные отрасли и возобновляемую энергетику. Последовательное и повсеместное финансовое стимулирование рынка экологических технологий необходимо для минимизации рисков, обусловленных колебаниями макроэкономики. В свою очередь, снижение уровня макроэкономического риска позволит в будущем привлечь инвесторов для реализации энергетически-сбалансированных проектов;

4) применение внутреннего аудита с целью определения эффективности внедрения энергосберегающих технологий. Как совокупность мер организационного, правового, технического, технологического, экономического и иного характера, энергоаудит направлен на снижение объема использования энергоресурсов при сохранении полезного эффекта. Полезный эффект может измеряться как объем произведенной продукции, выполненных работ, оказанных услуг;

5) приобщение населения к вопросам ресурсосберегающих технологий. Охват большинства людей, личная осознанность, планомерный ввод рыночных механизмов, стимулирующих изменение потребительского поведения по отношению к экотехнологиям, должны способствовать корректировке социальной модели поведения и облегчить адаптацию населения к использованию энергоэффективных технологий [6, с. 47].

Туристскую отрасль невозможно представить без гостиничного комплекса, который является наиболее распространенным, сложным и энергозатратным ее компонентом. Как основополагающий компонент туризма предприятия гостиничного сервиса являются крупными потребителями энергетических ресурсов и включают в себя систему освещения, отопления, водоснабжения, канализации, телефонных и интернет-сетей.

Экономия средств, посредством повышения энергоэффективности, позволяет снизить себестоимость гостиничных услуг, что в дальнейшем положительно сказывается на финансовых показателях отеля и, прежде всего, на прибыли. В таблице приведен сравнительный анализ со- 
отношения издержек, понесенных крупной мировой гостиничной сетью Radisson по реализации энергосберегающих программ, и экономии от внедрения энергоэффективных и энергосберегающих технологий $[4$, с. 4$]$.

Таблица

Сравнительная характеристика затрат на энергосбережение и полученной экономии отелями Park Inn в РФ, тыс. руб.

\begin{tabular}{|l|c|c|}
\hline \multicolumn{1}{|c|}{ Название отеля } & $\begin{array}{c}\text { Затраты на реализацию } \\
\text { мероприятия }\end{array}$ & $\begin{array}{c}\text { Планируемая экономия } \\
\text { за 5 лет }\end{array}$ \\
\hline $\begin{array}{l}\text { Park Inn by Radisson } \\
\text { Прибалтийская, Санкт-Петербург }\end{array}$ & 3000,0 & до 14000,0 \\
\hline $\begin{array}{l}\text { Park Inn by Radisson } \\
\text { Пулковская, Санкт-Петербург }\end{array}$ & 1866,6 & 2885,0 \\
\hline $\begin{array}{l}\text { Park Inn by Radisson } \\
\text { Невский, Санкт-Петербург }\end{array}$ & 827,4 & 2802,6 \\
\hline $\begin{array}{l}\text { Park Inn by Radisson, } \\
\text { Мурманск }\end{array}$ & 140,0 & 1575,0 \\
\hline $\begin{array}{l}\text { Рark Inn by Radisson, } \\
\text { ВеликийНовгород }\end{array}$ & 749,0 & $\mathbf{5 2 8 5 , 0}$ \\
\hline
\end{tabular}

Обрашаясь к исследованиям, проводимым агентством Front \& Sullivan, совокупные расходы по эксплуатации гостиничных объектов в течение 50 лет превышают его первоначальную строительную стоимость в 4 раза. Большая часть расходов при этом приходится на освешение. Начиная с 2011 года на объектах туристской инфраструктуры энергосберегающие лампы приходят на смену устаревшим лампам накаливания. Однако помимо освещения, организациям, занятым в сфере туризма, настоятельно рекомендуется обращать внимание на другие источники энергосбережения и энергоэффективности [9].

Ни для кого не секрет, что все большее распространение получают «умные» системы освещения. Основной энергосберегающий эффект путем автоматического запуска освещения в те моменты, именно оно действительно необходимо. Эффект достигается путем работы выключателя, который оснащен оптическим датчиком и микрофоном. В светлое время суток при высоком уровне освещенности система отключается. При наступлении сумерек происходит включение микрофона. В случае если в пределах 5 м возникает шум (топот шагов, шарканье или звук открываемой двери), свет будет автоматически включен и загорится энергосберегающий светящий элемент, который будет освещать пространство до тех пор, пока человек находится в помещении [10, с. 5$]$.

Обзор литературы по заданной тематике позволяет выявлять солидарность авторов в вопросе энергосбережения. По мнению Е. С. Виноградова и В. Е. Котельникова, одно применение энергосберегающих ламп позволит сократить уровень вредного воздействия, снизить экологическую нагрузку и получить положительный финансовый эффект [1, с. 28].

За пределами России существует значительное число организаций, деятельность которых направлена на разработку и внедрение систем экологического менеджмента. Одной из таких организаций является British Airways Holidays (BAH) - один из крупнейших мировых авиаперевозчиков и туроператоров. Компания проводит регулярный мониторинг отелей Карибского бассейна, который является популярным туристским регионом. Опираясь на результаты мониторинга, ВАН оказывает содействие средствам размещения с хорошим экологическим менеджментом, а также осуществляет контроль технологий управления в гостиничной индустрии. Деятельность компании, направленная на подготовку критериев экологического менеджмента, является первой попыткой создания единых для всех гостиниц требований. В результате путешественник должен получить возможность самостоятельно и сразу определять уровень сервиса и качества услуг, на 
который он может рассчитывать в гостинице. При этом неоспоримым преимуществом системы менеджмента с точки зрения энергоэффективности качества является возможность членства в указанной организации и бесплатная процедура сертификации.

Рассматривая частные случаи ресурсосбережения туристско-рекреационного комплекса, стоит обратиться к энергосберегающей фурнитуре. Конкретными путями снижения энергоемкости систем жизнеобеспечения на объектах туристской инфраструктуры могут служить автоматизация электрооборудования, в том числе внедрение энергоэффективных систем освещения, оснащение помещений ванных комнат датчиками движения, установка автоматических выключателей света, установка единой системы отопления. В первую очередь такого рода нововведения - это продуманная система ресурсо- и энергосбережения, включающая жесткие стандарты экономии ресурсов и широкое использование альтернативных источников энергии. Эта черта в первую очередь связана с недостаточной ресурсообеспеченностью развитых стран и активной политикой, направленной на стимулирование энергосбережения.

Многие отели уже сейчас используют солнечную энергию не только для прямого подогрева воды, но и для получения электрической энергии. Проведенные исследования показывают, что благодаря внедрению и использованию новых экологических методов работы (например, подогрев воды посредством солнечной энергии) и сравнительно небольшим инвестициям в туристический комплекс, например ресторанный и гостиничный бизнес, можно сократить потребление электроэнергии на 10-25\%, потребление воды - на $30 \%$ [5, с. 23].

Рассмотрим отечественную практику внедрения энергосберегающих, энергоэффективных и экологических технологий. С лета 2010 года в России начала действовать международная программа добровольной сертификации гостиниц, бизнес-центров, хостелов, пансионатов, баз отдыха и кемпингов «Зеленый ключ» (Green Key). Разработчик программы - Международная организация по экологическому образованию. Цель разработки заключалась в повсеместном распространении и внедрении экологических идей в туристской индустрии.

Деятельность гостиниц, прошедших сертификацию по программе «Зеленый ключ», соответствует установленному списку обязательных и факультативных критериев, например: сокращение потребления электроэнергии, воды, химической продукции, уменьшение количества отходов, передача отходов на вторичную переработку. Отели - участники программы проходят проверку, которая проводится экспертом. Средства размещения, сертифицированные программой, соответствуют высоким экологическим стандартам, отличаются ответственным подходом к бизнесу и вносят активный вклад в защиту окружающей среды [3, с. 2].

Обращаясь к общей практике можно отметить, что применение энергоэффективных технологий на предприятиях туристской отрасли способно снизить затраты на энергоемких участках до $50 \%$, что позволяет не только сохранить достаточные мощности, но и снизить размер коммунальных платежей. Использование экологически безопасных материалов позволяет повысить аттрактивность предлагаемого средствами размещения пакета услуг, поскольку отвечают запросам по удовлетворению запросов клиентов с точки зрения повышающегося спроса на так называемые «зеленые» материалы и технологии [8, с. 156]. В настоящее время 30-40 \% расходов любого объекта туристской направленности составляют расходы, связанные с оплатой электроэнергии, отопления и воды. Ежегодно данная нагрузка увеличивается за счет повышения стоимости коммунальных услуг.

Несмотря на то что для развития экономики характерна цикличность, производство и потребление электроэнергии имеет тенденцию к непрерывному увеличению. На рис. отражается фактическая и прогнозная динамика производства электроэнергии и электропотребления в России в период с 2008 по 2030 гг. В соответствии с прогнозом, к концу 2030 года реальное производство электроэнергии составит 1860 млрд кВт/час, тогда как планируемое производство 1554 млрд кВт/час. Графики наглядно отражают несбалансированность экономического роста, производства и потребления электроэнергии. 


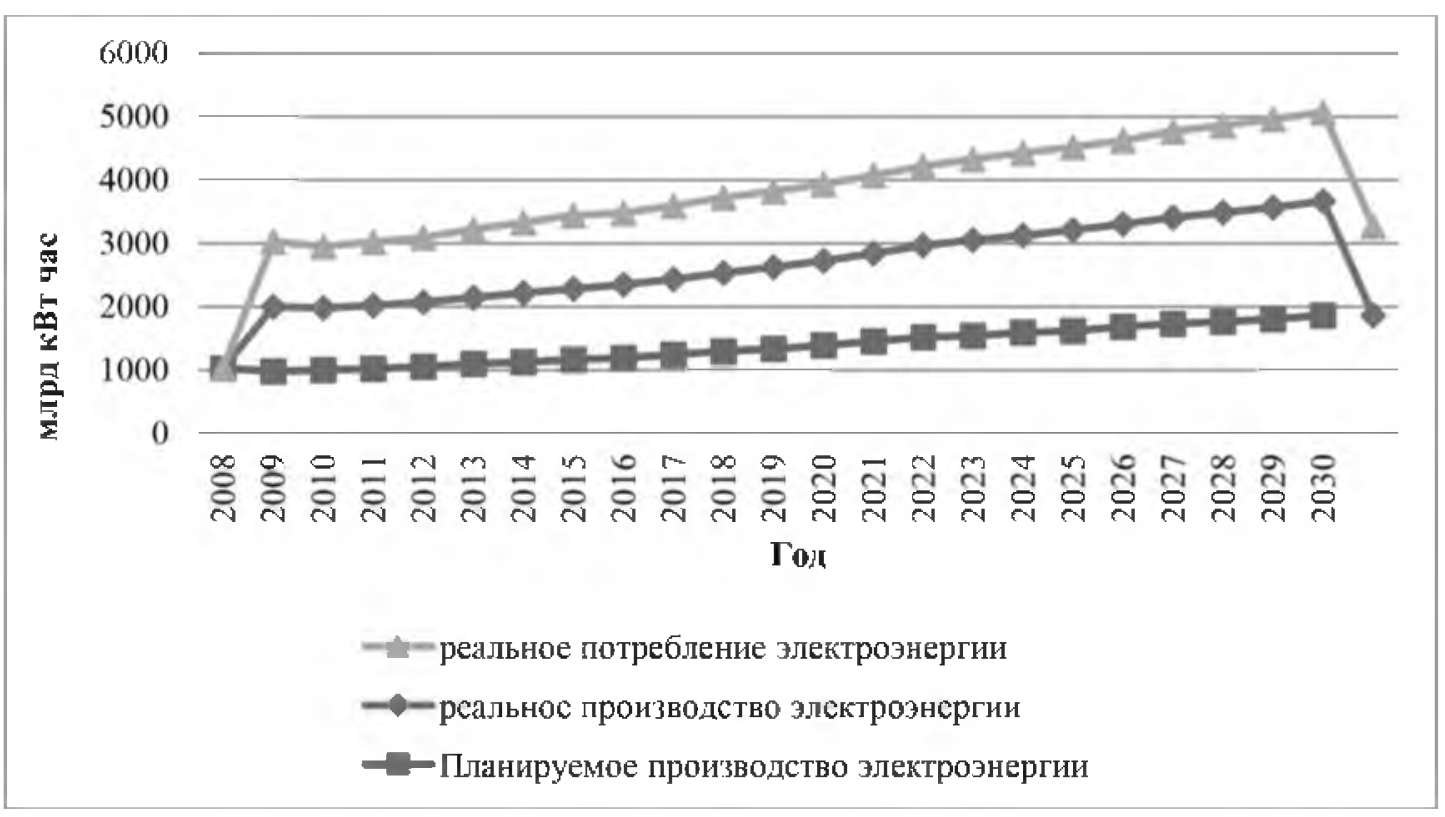

Рис. Производство электроэнергии и электропотребление в период с 2008 по 2030 гг, млрд кВт/час

Важную роль играет макроэкономическая оценка деятельности России в качестве туристской дестинации, которая отражает аттрактивность страны как направления въездного туризма. Практика показывает, что относительно невысокий рост затрат предприятий туристской отрасли в целом и гостиничного сервиса в частности обычно отмечается в сезонный период (май - сентябрь). В оставшееся время объем въездного туризма резко сокращается (за исключением периода новогодних праздников), что, естественно, вызывает дополнительные финансовые нагрузки в виде затрат на содержание гостиничных объектов.

Однако не все предприятия туризма готовы приобщиться к внедрению энергоэффективных, энергосберегающих технологий для оптимизации расходов и увеличения объемов прибыли. Данная тенденция, по нашему мнению, обусловлена давно известными и, к сожалению, практически не изменяющимися обстоятельствами:

1) архаичным менеджментом;

2) отсутствием финансирования;

3) обветшанием материально-технической базы средств размещения;

4) отсутствием развитой и продуманной инфраструктуры дополнительных рекреационных сервисов;

5) отсутствием законодательных инструментов для грамотного регулирования деятельности в сфере энергосбережения и энергоэффективности, применительно к оказанию туристических услуг.

Кардинальное решение проблемы энергосбережения в туристской сфере не представляется возможным без создания в стране и внедрения на каждом уровне прагматичного и результативного мотивационного механизма энергосбережения. Стимулирующий механизм энергосбережения должен наладить прямую связь между поставщиками и потребителями электроэнергии.

Основными мерами, обеспечивающими снижение энергопотребления в гостиничном бизнесе, по нашему мнению, должны стать:

1) контроль качества проектирования гостиничных комплексов, в том числе контроль соответствия нормам теплозащищенности и энергосбережения; 
2) контроль качества проведения строительно-монтажных работ с точки зрения норм энергоэффективности и энергосбережения инженерного оборудования и систем;

3) тщательный выбор оборудования, отвечающего рациональному сочетанию безопасности, комфорта и затрат на энергопотребление;

4) автоматизация инженерных систем, направленная на снижение неоправданных затрат;

5) оптимизация затрат на оплату жилищно-коммунальных услуг и энергоресурсов.

Заключение / Conclusion. Резюмируя сказанное, стоит отметить, что основной задачей внедрения энергосберегающих и энергоэффективных технологий на предприятиях туризма является снижение себестоимости туристских услуг с целью повышения ценовой привлекательности оказываемых предприятиями туризма услуг и увеличения прибыли предприятий туризма от реализации туристских услуг.

Грамотная, прагматичная политика в сфере энергосберегающих технологий поможет превентивно ликвидировать ряд проблем, отягощающих материально-техническую базу предприятий туризма.

\section{ЛИТЕРАТУРА И ИНТЕРНЕТ-РЕСУРСЫ}

1. Виноградов Е. С. Теоретические аспекты внедрения экологических инноваций в гостиничном бизнесе // Сервис в России и за рубежом. 2015. Т. 9. № 4 (60). С. 27-38.

2. Зуденкова С. А. Потенциал энергосбережения в жилищно-коммунальном хозяйстве московского региона // Сервис Plus. 2008. № 1. С. 35-39.

3. Котельников В. Е. Почему отели становятся «зелеными»? // Зеленый город. 2014. № 5. С. 1-4.

4. Орлова А. М. Ресурсосберегающие технологии: роль в повышении эффективности гостиничного предприятия и проблемы внедрения // Современные научные исследования и инновации. 2014. № 12-2 (44). C. 89-96.

5. Отто О. В. Влияние экологического фактора на развитие гостиничного бизнеса. // Наука и туризм: стратегии взаимодействия. 2017. № 5. С. 22-28.

6. Печерица Е. В., Шевченко М. И. Инновационные технологии в гостиничном бизнесе. СПб.: Изд-во СПбГУСЭ. 2013. 128 с.

7. Печерица Е. В. Теоретические аспекты ресурсосберегающих технологий в гостиничном бизнесе // Технико-технологические проблемы сервиса. 2014. № 2 (28). С. 95-100.

8. Рыкун Г. А., Григориадис А. П. Основные направления качественного преобразования современного гостиничного хозяйства // Современные проблемы инновационного развития науки: сборник статей Международной научно-практической конференции. Уфа, 2016. С. 153-158.

9. Российский союз индустрии. Туристический бизнес [Электронный pecypc]. URL: http://tourfaq.net (дата обращения 25.08.2018)

10. Сумзина Л. А., Максимов А. В., Литвиненко А. А., Кудров Ю. В. Тенденции развития отрасли энергосберегающих технологий // Науковедение: интернет-журнал. 2015. Т. 7. № 1 (26). С. 98.

\section{REFERENCES AND INTERNET RESOURCES}

1. Vinogradov E. S. Teoreticheskie aspekty vnedreniya ehkologicheskih innovacij v gostinichnom biznese (Theoretical aspects of implementation of environmental innovations in the hotel business) // Servis $\mathrm{v}$ Rossii i za rubezhom. 2015. T. 9. № 4 (60). S. 27-38.

2. Zudenkova S. A. Potencial ehnergosberezheniya $v$ zhilishchno-kommunalnom hozyajstve moskovskogo regiona (Energy saving potential in housing and communal services of the Moscow region) // Servis plus. 2008. № 1. S. 35-39.

3. Kotelnikov V. E. Pochemu oteli stanovyatsya zelenymi (Why do hotels become "green"?)? // Zelenyj gorod. 2014. № 5. S. 1-4.

4. Orlova A. M. Resursosberegayushchie tekhnologii: rol v povyshenii ehffektivnosti gostinichnogo predpriyatiya i problemy vnedreniya (Resource-saving technologies: the role in improving the efficiency of the hotel enterprise and the problems of implementation) // Sovremennye nauchnye issledovaniya $i$ innovacii. 2014. № 12-2 (44). S. 89-96. 
5. Otto O. V. Vliyanie ehkologicheskogo faktora na razvitie gostinichnogo biznesa (The impact of environmental factors on the development of the hotel business) // Nauka i turizm: strategii vzaimodejstviya. 2017. № 5. S. 22-28.

6. Pecherica E. V. Shevchenko M. I. Innovacionnye tekhnologii v gostinichnom biznese (Innovative technologies in the hotel business). SPb.: Izd-vo SPbGUSEH, 2013. $128 \mathrm{~s}$.

7. Pecherica E. V. Teoreticheskie aspekty resursosberegayushchih tekhnologij $\mathrm{v}$ gostinichnom biznese (Theoretical aspects of resource-saving technologies in the hotel business) // Tekhniko-tekhnologicheskie problemy servisa. 2014. № 2 (28). S. 95-100.

8. Rykun G. A., Grigoriadis A. P. Osnovnye napravleniya kachestvennogo preobrazovaniya sovremennogo gostinichnogo hozyajstva (The main directions of qualitative transformation of modern hotel industry) // Sovremennye problemy innovacionnogo razvitiya nauki. Ufa, 2016. S. 153-158.

9. Rossijskij soyuz industrii. Turisticheskij biznes (Russian Union of industry. Tourist business) [Ehlektronnyj resurs]. URL: http://tourfaq.net

10. Sumzina L. A., Maksimov A. V., Litvinenko A. A. Kudrov Yu. V. Tendencii razvitiya otrasli ehnergosberegayushchih tekhnologij (Trends in the development of energy-saving technologies) // Naukovedenie. 2015. T. 7. № 1 (26). S. 98.

\section{СВЕДЕНИЯ ОБ АВТОРАХ}

Гузикова Людмила Александровна, доктор экономических наук, профессор, Санкт-Петербургский политехнический университет Петра Великого, г. Санкт- Петербург. E-mail: guzikova_la@spbstu.ru

Колесников Александр Михайлович, доктор экономических наук, профессор, кафедра экономики высокотехнологичных пронзводств, Санкт-Петербургский государственный университет аэрокосмического приборостроения, г. Санкт-Петербург. E-mail: 9843039@mail.ru

Шехматова Ксения Олеговна, магистрант, Санкт-Петербургский политехнический университет Петра Великого, г. Санкт-Петербург. E-mail: 9843039@mail.ru

\section{INFORMATION ABOUT THE AUTHORS}

Lyudmila A. Guzikova, Doctor of Economic Sciences, Professor, Peter the Great St. Petersburg Polytechnic University, St. Petersburg. E-mail: guzikova_la@spbstu.ru

Alexander M. Kolesnikov, Doctor of Economic Sciences, Professor, Department of Economics of high-tech industries, St. Petersburg state University of aerospace instrumentation, St. Petersburg. E-mail: 9843039@mail.ru

Ksenia O. Shekhmatova, master's degree student, Peter the Great St. Petersburg Polytechnic University, St. Petersburg. E-mail: 9843039@mail.ru 